\title{
An award and a legacy
}

VERSION FRANÇAISE À LA PAGE 142

See related ARTICLE ON PAge 143

Although every issue of CFEM is special, this one is particularly so as it includes the first winning submission for the annual Penelope Gray-Allan Memorial CFEM Writing Award. The winner of this year's award is Dr. Michelle Tousignant, a resident from the University of Alberta CFPC Emergency Medicine Residency Program. Dr. Tousignant has written a very moving essay, the subject of which is strikingly poignant given the tragic loss the Canadian emergency medicine community, Canadian Association of Emergency Physicians (CAEP), and CFEM suffered in early 2010 with the untimely death of CFEM's then managing editor, Penny Gray-Allan.

The Penelope Gray-Allan Memorial CFEM Writing Award was jointly established by the CAEP Board and the CFEM Editorial Board as a fitting legacy to Penny. It honours the best humanity submission from a Canadian RCPS or CFPC emergency medicine resident. Beyond publication of their submission, the award winner receives registration, travel, and accommodation for the CAEP annual conference, this year in St. John's, Newfoundland. Each year, CFEM readers can now look forward to reading the winning submission in the May issue of the journal.
We congratulate Dr. Tousignant on her outstanding publication and accomplishment, and we thank the many other residents who submitted papers for this competition, all of which were insightful and moving. The quality of the submissions in this inaugural year of the award bodes well for the poise, perception, and empathy of the next generation of Canadian emergency physicians. We also thank the members of the blinded review committee, Drs. Jim Ducharme, Jeff Freeman, and Peter Toth, for their expertise in selecting this year's winner.

Those who worked with Penny on the CFEM Editorial Board, and the many authors and reviewers with whom she interacted during her years at CFEM, will recall that as much as she loved science and precise verbiage, Penny valued the human side of medicine and the close relationships she established through her work above all else. Penny, wherever you are, we hope this year's winning paper brings a smile to your face. It certainly did to ours.

Riyad B. Abu-Laban, MD, MHSc

Senior Associate Editor, CFEM

Chris Evans, MD

Past President, CAEP 